breathing, when asleep, was accompanied by a loud stertor, or a species of snoring, which could be heard in the neighbouring room. He had a frequent and urgent cough, with free expectoration.

Both the stethoscopic signs and symptoms led me to think that, either from the penny passing down, or from some other cause, injury had been done to the larynx; or I thought it just possible that the coin was lodged somewhere in the forepart of the pharynx, giving rise to chronic inflammation of the mucous membrane of the larynx and trachea. Under treatment by tonics and anodynes, his general health improved, the cough became less troublesome, and at the end of the holidays he returned to school. I saw him again in December of the same year, and found very little change in his condition.

During the next two years (1865-1866), the symptoms of the laryngeal and tracheal affection remained nearly stationary; but he was evidently losing strength, and I could not help fancying that this state of ill-health was in some way due to the retention of the penny.

At the conclusion of 1867 , a marked tendency to disease of the lungs showed itself; and he continued so unwell after his return to school, that I advised his mother to bring him home. I now found that $I$ had to deal with a case of incipient phthisis; and Dr. Cameron, who saw him in consultation with me in May 1868, coincided in that opinion. By means of a generous diet, tonics, anodynes, and Dobell's pancreatic emulsion, he received benefit; but his improvement was still more striking from full doses of cod-liver oil, carbonate of ammonia, and Battley's sedative. Having gained sufficient strength, he took two voyages to the Mediterranean, from which he returned with great amelioration of the chest-disease, the condition of the larynx and trachea attracting but slight notice. There being now decided convalescence, I proposed that he should go on a trial voyauge to sea, to the Brazils, whence he returned in very good general health about the beginning of December 1869 .

Continuing to feel much interest in the casc, 1 requested Dr. Cameron to examine him in the following January, and received the following particulars. He found his general health good, and that he had gained flesh and strength. There were no traces of the pulmonary lesion which had excited our apprehension in 1868; but the voice was fecble, and had a harsh stridulous sound, which was also audible when he breathed. He suffered from occasional cough, which, like the voice, was harsh and stridulous. The expectoration was scanty, and sometimes streaked with blood. He had no difficulty or pain in swallowing unless the morsel of food were unusually large; but he laid no stress on this symptom. The tonsils were enlarged, and on each side of the neck were a few enlarged and painful cervical glands.

It seemed to I)r. Cameron, on considering all the circumstances of the case, but especially the peculiar laryngeal symptoms, that they were inconsistent with ordinary disease of the larynx; and it occurred to him that, possibly, they might be due to the impaction in, or near the organ, of the penny which, it was supposed, had been removed at the time of the accident. An examination with the laryngoscope confirmed his suspicion by revealing the following appearances, which are described as they were seen reflected in the mirror of the instrument.

In the upper part was the epiglottis, considerably altered in shape, size, and position; its apex being bent forwards and downwards, the edges curled inwards on themselves (like the mouth of a pitcher), and the base-much enlarged-losing itself in the arytæno-epiglottidean folds : these were likewise much swollen. In the centre of the image was the upper opening of the larynx, wider and deeper th: $n$ in health and the vocal chords, the play of which, during the movements of respiration, was distinctly perceptible. All these parts were unusually vascular. Next was seen, stretching transversely across this opening, an object with a metallic lustre : it was imbedded below and on each side in the swollen arytæno-epiglottidean folds; and, measured by the eye,

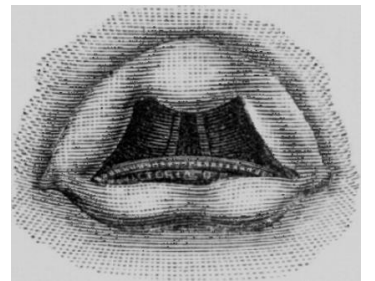

seemed about three-quarters of an inch in length, and one-eighth of an inch in breadth at the centre.* Dr. Cameron identified this at once as the rim of the penny which had been swallowed in 1864. At the time of the accident it had probably been forced into the opening of the larynx,

\footnotetext{
* The woodcut must be regarded rather as a diagram than as an actual drawing
} of the parts. and, gradually sinking lower and lower, had become fixed into its posterior wall.

From my knowledge of the case, I readily believed in this discovery of the long-lost penny; which I had also the opportunity of seeing, on several occasions, in situ, by means of the laryngoscope. Mr. Minshull, who was present during some of these examinations, formed the same opinion as to the position of the coin.

The exact situation of the penny having been thus satisfactorily determined, it was resolved, in consultation with Dr. Cameron and Mr. Minshull, to remove it without delay. The mode devised for operating consisted in passing down the forefinger of the left hand, as a guide, behind the epiglottis; then carrying the beak of a forceps specially designed for the purpose by Mr. Minshull and myself in the right hand over the tongue and round the base, at the back of the epiglottis, so as to seize the edge of the coin. On the 2gth of January, the operation was performed by Mr. Minshull, in the presence of, and assisted by, Dr. Cameron, Mr. Hamilton, Mr. Little of the Southern Hospital, and myself. With considerable dexterity, Mr. Minshull fixed the blades of the forceps on the rim of the penny and extracted it, though not without some difficulty from its position. Its removal was attended by great pain; and for a few moments, owing to the obstruction of the glottis, suffocation seemed imminent. After the operation, a little blood and mucus were expectorated, and the patient soon began to experience the anticipated relief.

The penny was of the 186r coinage, of a dark-green colour, and eroded on the surface, which presented, with the aid of a lens, a general "honey-combed" appearance. It weighed eighteen grains less than a well-worn coin of the same date; their respective weights being one hundred and forty-six to one hundred and twenty-eight grains-a difference which, we may infer, represents the loss undergone by the metal.

Subsequent Progress.--On examination with the laryngoscope a few days after the operation, it was found that the swelling and vascularity of the parts surrounding the laryngeal opening had much diminished; but there was now observed, on each side, in the arytæno-epiglottidean folds, and corresponding with the previous position of the penny, a clean-cut indentation or notch-evidently the spaces left vacant by its removal.

At the present date (June 18 th), these clefts, though partially filled up, can still be distinctly identified, and the surrounding parts have not yet regained their normal condition. The boy's voice continues feeble and somewhat harsh, but it has lost its stridulous character: possibly, owing to the injury done to the larynx, its natural tone may never be completely restored. His health, in other respects, is very good.

The after-treatment consisted in the occasional application to the larynx, by means of the laryngeal brush, of a solution of tannic acid in glycerine, and the administration of tonics.

POSTSCRIPT. - A case has recently occurred in the Southern Hospital, showing the value of the laryngoscope in detecting foreign bodies in the larynx. A woman came to the Hospital, stating that she had swallowed a piece of bone, which she believed was in her throat. A probang was passed, with apparent relief, and she went away. Next day, however, she returned, still complaining; and as the voice and breathing were slightly stridulous, Dr. Cameron was requested to examine her with the laryngoscope, when he detected a small piece of bone stretched across the glottis, from before backwards, so as to cover one of the vocal chords. It was readily removed by $\mathrm{Mr}$. Hamilton, one of the honorary surgeons of the Hospital, with a pair of long and sharply curved forceps, the blades of which opened laterally.

\section{A CASE OF SPONTANEOUS RUPTURE OF THE UTERUS DURING LABOUR.}

\author{
BY E. R. DE N T O N, M.R.C.S.E., L.S.A., \\ Surgeon to the Leicester Provident Dispensary.
}

ON July 2 Ist, I was hastily summoned by a midwife to assist in a case of labour. The patient was reported to have fainted. On arrival, I found her undelivered and in articulo mortis. On vaginal examination, the fcetal head was found presenting normally, and far advanced towards the completion of the second stage. The outlet appeared to be of nor$\mathrm{mal}$ size ; and there were no signs of deformity of pelvis or protracted labour. I immediately made several attempts to deliver by means of the short forceps. These were unsuccessful, from the collapsing of the cranial bones, which allowed the blades to slip off on very moderate traction. By this time the patient was dead; and as there was evidence of the death of the child also, the performance of the Crsarean section did not appear to be indicated. The non-recession of the head and body 
of the child into the abdominal cavity induced me to have the hope that the case was other than one of rupture of the uterus. However, on being allowed to make a post mortim examination, this at once revealed the true state of affairs.

The husband informed me that the present was his wife's seventh confinement, and that the previous ones had been free from any casualty requiring surgical interference. The health of the patient for the last $f e w$ weeks of her pregnancy had been indifferent, she having suffered from great debility. The midwife-a woman of some experiencestated that she was called at 9 o'clock the previous evening to attend the deceased, and that the labour had progressed favourably up to within an hour of my being summoned (this was at 2 A.M.) At that time (1 A.M.), she experienced three very strong "good" pains, though her cries during them were not unusually great; after which she imme diately complained of feeling very faint. The pains ceasing altogether, and the faintness increasing notwithstanding the usual restoratives were applied, she at once requested that further assistance should be obtained. It should be mentioned that no ergot was administered during the labour.

Post Mortem Examination Seventeen Hours after Death. - The deceased was 40 years old. The body was muscular and well nourished. Post mortem rigidity was nearly complete. There were no signs of external hæmorrhage. On laying open the abdomen, a small clot was found lying upon the intestines, and a considerable quantity of bloody serum was present in the cavity of the abdomen. The uterus appeared to be entire; but, on closer examination, the peritoneum covering the anterior aspect was found distended; and underneath, and visible through it, was a mass of coagula diffused between the peritoneum and the muscular portion, which towards the cervix was thin and attenuated. On carefully removing the mass of coagula, the nates and side of the child came into view, whilst the fundus of the uterus was contracted upon itself, and the placenta lay detached but in apposition with it, the rest of the space being occupied by coagula. On examining the muscular walls, a longitudinal rent, several inches in length, was found on the anterior aspect of the uterus, though not extending into the vagina, the edges on both sides being rugged and torn. The child was removed with considerable difficulty, as it was a very large one, weighing about twelve pounds, and fully developed.

REMARKS. - The above case is unusually interesting and instructive, inasmuch as one prominent and characteristic symptom of rupture, as stated by authorities, was entirely wanting; namely, the sharp cry attendant on agonising pain. As stated by the midwife, and also by the mother of the deceaser, nothing unusual was complained of by the patient except great faintness; but she had from the time of the last pain a presentiment of impending death, as she gave several directions to her mother respecting the future welfare of her family and other matters of family importance, after which she gradually sank.

This case is, however, not altogether a rare one, as Dr. Radford has reported two cases where rupture of the uterus was complete without laceration of the peritoneal covering; and Dr. Churchill also states that he assisted at a post mortem examination in which no rupture of the uterus was discovered, but where great effusion of blood beneath the peritoneal covering was found ; but even in his case the symptoms accompanying it were sudden excruciating pain in the abdomen, with vomiting, collapse, etc.

In Waller's note to Denman's Introduction to Midivifery, pp. 262, two cases are mentioned in which rupture of the uterus happened without any peculiar sensation being experienced, so that the time of rupture could not be ascertained : he also states that external hæemorrhage is not an invariable symptom when the head is low down.

With this evidence and under these considerations it becomes a mat. ter of mystery as to the immediate cause of so fatal an accident; and any evidence which will tend to elucidate the true cause it is our duty to bring before the members of our profession.

Donation. - Thomas Rochester, Esq., of Whalton, near Morpeth has instructed his bankers (Messrs. Hodgkin, Barnett, and Co.) to pay over the munificent donation of $£ \mathbf{1 2 , 0 0 0}$ to various local and nationa institutions, including Morpeth Dispensary, 1,000 ; Newcastle Dispensary, $f, 000$; Deaf and Dumb Asylum, Newcastle, $£$ r,,$\infty$; Hos pital for Sick Children, Newcastle, $£$ r,o00; Blind Asylum, Newcastle f, $1, \infty 00$.

The Contagious Diseases Acts (Women). - At the Canterbury Petty Session, seven women were summoned for not having submitted themselves for medical examination. In six of the cases orders were made for the women to attend for twelve months; in the other, the defendant was committed to prison for fourteen days, as she positively refused to undergo the ordeal.

\section{REPORTS}

or

MEDICAL AND SURGICAL PRACTICE IN THE HOSPITALS OF GREAT BRITAIN.

\section{$\checkmark$ UNIVERSITY COLLEGE HOSPITAL.}

THE INTESTINES AND ABDOMINAL VISCERA CUT THROUGH BY THF PASSAGE OF A RAILWAY-TRAIN OVER THE BODY, WITH SCARCE ANY INJURY TO THE ABDOMINAL WALLS.

R. A., aged I9, a telegraph clerk, was seen near Camden Road Station at II.50 on the night of Saturday, June 26th. He was then sober, had over two pounds of money in his possession, and stated his intention of going to Euston Square by the 11.56 train. Although he was known to the officials, and there were very few passengers, no one saw him get in at Camden Road, or get out at Euston Square. The ticketcollector also said that he should have recognised him at once had he been in the train. The train, after discharging at Euston, was backed into a shed; and, as two shunters who had performed this duty were returning along the line which the train had just passed over, they found R. A. lying on his back just inside the station, straight across the outer rail, with his head between the rails, and his hat tilted over his eyes. He was alive when found, but died in a few minutes. The body was at once brought to University College Hospital. It was clothed in a long jacket, waistcoat and trousers of thick coarse cloth, on which the marks of the carriage-wheels were plainly visible. Only a few pence were found in his pockets. There was not the smallest wound on the body, and only a few abrasions of cuticle across the abdomen. After some hours, pretty extensive ecchymoses appeared. On opening the abdomen, all the abdominal muscles were found completely cut through horizontally, retracted, and curled up, leaving a gap five or six inches wide. The back muscles were in the same condition. The right kidney was cut in half. The transverse colon and a large piece of the ilium were lying free in the abdomen; and the body of the third lumbar vertebra was crushed literally to powder; everything was divided except the skin. The rest of the body was healthy.

The case excited a good deal of interest at the time, and remarks on its occurrence appeared in most of the daily papers. Some suggested suicide; but suicides generally put the head or neck on the line. The position of the body, laid out quite at right angles to the rail, with the hat on the face, favoured this view; but no motive was made out Many seemed to think he had been stunned, robbed, and thrown out but the absence of any bruises, and the position of the body, almost negatived this view. His money was loose in his pocket, and probably fell out in the moving. Lastly, the driver declared that it was impossible that he could have been run over at all; for, besides the three carriages and break-van, his engine weighed over thirty tons, and must infallibly have cut him in half ! So it did, except the skin, which was protected by three layers of thick cloth, etc. Neither driver nor guard felt any shock as the train passed over him. Altogether, the case presents-several points of great medico-legal interest.

\section{LIVERPOOL INFIRMARY FOR CHILDREN.}

CASE OF GENERAL DISEASE OF THE LYMPHATIC SYSTEM : WITH REMARKS ON ITS PATHOLOGY.

By Richard Catos, M.B., Honorary Assistant-Physician to the Infirmary.

Louis J., aged 8, was brought to the Children's Infirmary on I5th January, 1870, with the following symptoms and history. Early in 1868, his health became slightly impaired; a year later, one or two enlarged glands were felt in the neck on the right side. These increased in size, and others appeared. Constitutional treatment and the local application of iodine were employed, but without benefit ; the glands increased steadily, and the patient lost flesh and strength.

At the time of his appearance at the Hospital, a large irregular nodular tumour existed under the skin of the neck, extending from the right mastoid process to the clavicle, and hanging downwards over the latter, to the extent of about an inch. The mass felt to the hand like a bunch of small grapes. The nodules were clearly defined, moved freely upon one another, and were not tender to the touch. They probably numbered about thirty. On deep pressure on the opposite side of the neck, two glands could be felt similarly enlarged. There was no further glandular affection externally. His voice was husky iriad been so for three months. On examining the pharynx, a prominence 